\title{
ОТРАЖЕНИЕ ЯПОНСКОЙ КУЛЬТУРЫ В ВИДЕОИГРАХ
}

\section{THE REFLECTION OF JAPANESE CULTURE IN VIDEOGAMES}

\section{O. Stolyarchuk}

Summary: This article is about importance Japanese culture in games for Europeans and how Japanese gaming companies integrates elements of Japanese culture in their products. In 70-80s Japanese game industry have influenced on not only economics of Japan, but on many other countries' aspects of life by adding parts of Japanese culture in their games, that is hypothesis of research. Research methods are analysis, synthesis and modeling. As a result of research, author makes the conclusion that nowadays Japanese videogames are not only kind of entertainment, but the art like cinematography and animation, too.

Keywords: Japan, culture, videogames, market, technologies, game industry, software, development.
T ермин игровая индустрия (game industry) является общепринятым в научных сообществах мира, в том числе в Японии, где соответствующее понятие (яп. ゲ 一 ム産業 гэ:му сангё) используется как среди исследователей феномена видеоигр, так и в официальных документах министерств и ведомств . Под игровой индустрией подразумевается отрасль экономики, в которой задействованы компании, связанные с производством аппаратного и игрового программного обеспечения (ПО), геймдизайном, продвижением и дистрибуцией компьютерных игр. К игровой индустрии не относятся автоматы для азартных игр (игорный бизнес), настольные игры и детские игрушки. [4, с.256].

Зарождение игровой индустрии в Японии происходило совместно с изменениями, пришедшимися на вторую половину XX в. В первую очередь следует отметить о влияние США и послевоенную оккупацию не только на политическую и экономическую жизнь Японии, но и на культуру. Контроль и финансовая поддержка со стороны американского правительства стали фундаментом для японского экономического чуда, что в свою очередь привело к потребительскому буму, в том числе на товары и услуги в сфере развлечений. [3, с. 204]

В условиях информационной эры индустрия игр стала одной из самых востребованных отраслей мировой экономики, являясь ключевым двигателем прогресса в отношении технологий. В настоящее время не утихают разговоры среди любителей видеоигр о том, что японские игры - что-то близкое нам, но и в то же время что-то отчуждённое, непонятное нам, людям, проживающим за

\author{
Столярчук Ольга Сергеевна \\ ФГБОУ ВО «Тихоокеанский государственный \\ университет», г. Хабаровск, \\ cool.khikari@gmail.com
}

Аннотация: В данной работе представлено исследование о том, как в период глобализации японские игровые компании интегрируют культуру Японии в свои продукты. Ещё в 1970-80-ых годах игровой индустрии страны восходящего солнца удалось повлиять не только на экономику страны в целом, но и на многие аспекты жизни в других странах путём внедрения в свои творения частицы японской культуры, что и является гипотезой. Методы исследования: анализ, синтез, моделирование. В результате работы автор приходит к выводу 0 том, что на сегодняшний день японские видеоигры являются не только досугом, но и видом искусства наряду с кинематографом и мультипликацией.

Ключевые слова: Япония, культура, видеоигры, рынок, технологии, игровая индустрия, программное обеспечение, развитие.

пределами самой Японии.

Игровая индустрия страны восходящего солнца продолжает активно развиваться, положив начало своего развития ещё в конце XX века. Сейчас игры представляют из себя не только развлечения или важную экономическую составляющую, но и так же огромный пласт культуры. Так или иначе, но благодаря погружению в атмосферу той или иной игры, мы сможем расширить свой кругозор о представлении культур других народов или даже проникнуться тем, что ранее считалось непонятным.

Для современных исследований в сфере гуманитарных наук понятие игровой индустрии является относительно новым, отчего и предполагает прежде всего углубиться в анализ самой специфики японских видеоигр и экономический подход, который поможет увидеть сложившуюся картину на игровом рынке и выделить продукты, сыскавшие наибольший успех в определённый период. Так, например, лучший балл на Metacritic (сайтагрегатор, собирающий отзывы о музыкальных альбомах, играх, фильмах, телевизионных шоу, DVD-дисках и мобильных играх) за 2020 год получила «Persona 5: Royal» (игра японской компании Altus) - 95 из 100, а «Final Fantasy XV» ( ролевой боевик, разработанный Square Enix)внезапно стала лидером по количеству ретвитов - 924 тысячи. [3]. Наиболее обсуждаемые игры в социальной сети «Твиттер» за 2020г. представлены на рисунке 1. Но всегда ли такой успех был присущ японскому рынку видеоигр? 
Несмотря на то, что в последнее время всё больше японских видеоигр становятся популярны на Западе (Dark Souls, Zelda, Nier: Automata, Persona 5), в середине 2000-ых в японской игровой индустрии произошёл кризис, вызванный тем, что японские разработчики намерено пытались угодить западным покупателям. В результате чего их творения теряли часть культурной идентичности и походили на то, что выпускают на Западе. По словам Йоко Таро (создателя «Nier»), главное отличие японского подхода к играм в отличие от европейского стремление японцев к сюрреалистическим и неясным художественным формам, в то время как европейцам больше близка реалистичность в играх. [1]. Именно из-за этой разницы японцы не рискнули и не привнесли чтото особенное на мировой рынок. Этому способствовало множество факторов: от исторических, социально-экономических, политических до культурных особенностей и трансформации национального сознания японцев. [3, с.203]. Вследствие чего, на тот момент ориентировались больше на западную аудиторию, нежели на развитие собственного подхода.

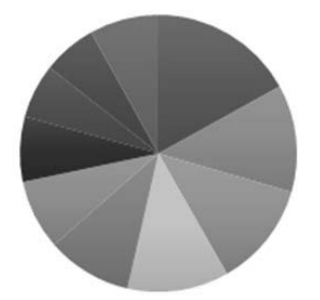

\begin{tabular}{|c|c|}
\hline Einal Fantasy XV & Animal Crossing New Horizons \\
\hline Cyberpunk 2077 & “ Call of Duty: Black Ops Cold War \\
\hline Fall Guys: Ultimate Knockout & Call of Duty: Warzone \\
\hline - Assasin's Creed:Valhalla & Eortnite \\
\hline - The Last Of Us Part II & a Ghost Of Tsushima \\
\hline
\end{tabular}

Рис 1. Наиболее обсуждаемые игры в твиттере за 2020г. [2].

Для многих людей Япония и по сей день остаётся страной, которую можно стереотипно охарактеризовать такими реалиями как «гейша», «сакэ», «кимоно», «сакура», «якудза» и «вата». Такое представление о стране восходящего солнца отчасти можно назвать верным, но дальше таких реалий кроется немало интересных аспектов японской культуры, о которых иностранцам мало что известно. Воплощение таких реалий зачастую наблюдается непосредственно в играх, благодаря которым игрок может узнать что-то новое о культуре и даже языке Японии.

В наше время гейш можно Киото, а девушки в традиционных кимоно запросто ходят по улицам нынешней японской столицы. Япония - пример страны, идущей в ногу со временем, но при этом верной своим тради- циям. Кроме того, молодые японки надевают кимоно в День Совершеннолетия, а маленькие дети - на праздник Сити-Го-Сан (досл. Перевод «Семь-Пять-Три»), во время которого мальчики трех и пяти лет и девочки трех и семи отправляются в синтоистский храм. К тому же, ношение традиционной одежды просочилось и в видеоигры. Юна из «Final Fantasy X» одета в фурисодэ, разновидность кимоно для незамужних девушек с удлиненными рукавами, а гейша Кохару, помогает главному герою игры «Killer Is Dead» отдохнуть между миссиями.

Одной из важных частей японской культуры, несомненно, является культ еды. Японская кухня за пределами самой Японии имеет немало почитателей и неудивительно, ибо она одновременно и сытная, и полезная. Всеобщий культ еды отражен в игровой индустрии. В «Ryu ga Gotoku Ishin!» можно не только ловить рыбу, но и готовить ее с помощью мини-игр. Зачастую в различных японских визуальных новеллах можно увидеть, как герои, поедая о-бэнто (небольшие ланчи), обсуждают повседневность.

Наряду с культом еды у японцев далеко не последнюю роль в культуре играет любовь к природе, гармонично сочетающаяся с любовью к еде. Например, когда осенью листья местного клена приобретают оттенки от темно-багрового до бледно-желтого, их начинают готовить в кляре. Такой удачный симбиоз является причиной, почему японские разработчики уделяют большое внимание тому, как выглядят локации в играх. Square Enix нарисовали совершенно чарующие пейзажи для «Lightning Returns: Final Fantasy XIII», а жители мира «Tales of Xillia» научились жить в гармонии с природой, и выглядит это не только красиво, но и символично.

Благодаря сплетению буддизма и синтоизма в культуре у японцев сформировалось своеобразное представление о смерти. После того, как его жизнь закончена, человек либо перерождается (по буддизму), либо становится частью мира духов и хранителем своей семьи (по синтоизму). Почти иллюстративным примером отношения японской религии к смерти является RPG-игра «Dark Souls», в которой имеется предельно восточный подтекст. Эта игра известна многим своей сложностью, за счёт которой игроку предстоит умирать довольно часто, но на смерти не наступает конец игрового процесса. Наоборот, «Dark Souls» даёт понять, что у тебя есть ещё одна попытка, ещё одна жизнь.

Отдельно стоит сказать и о мифах, особенно, страшных историях, являющихся одним из наиболее интересных пластов культуры Японии. Несмотря на то, что Япония известна сериями хоррор-игр «Resident Evil» (на яп. «Biohazard») и «The Evil Within» (на яп. «PsychoBreak»), большего расположения эти игры получили именно за 
пределами Японии, поскольку они, как и являются примерами игр, ориентированных на западную публику. Парадоксально, но использованием исконно японских мотивов в играх жанра ужасов чаще промышляют в продуктах западной игровой индустрии. Например, Альма из «F.E.A.R.» напоминает Садако [см. Рис. 2] из цикла романов Кодзи Судзуки «Звонок». Образ Садако в свою очередь навеян японской историей «Bancho Sarayashiki» («Поместье тарелок в Банчо»). В ней несчастная служанка Окику разбила тарелку из дорогого сервиза, за что хозяин сбросил её в колодец. Став призраком, девушка каждую ночь возвращалась в дом, считала тарелки и, не досчитавшись последней, начинала плакать, чем быстро свела хозяина с ума.
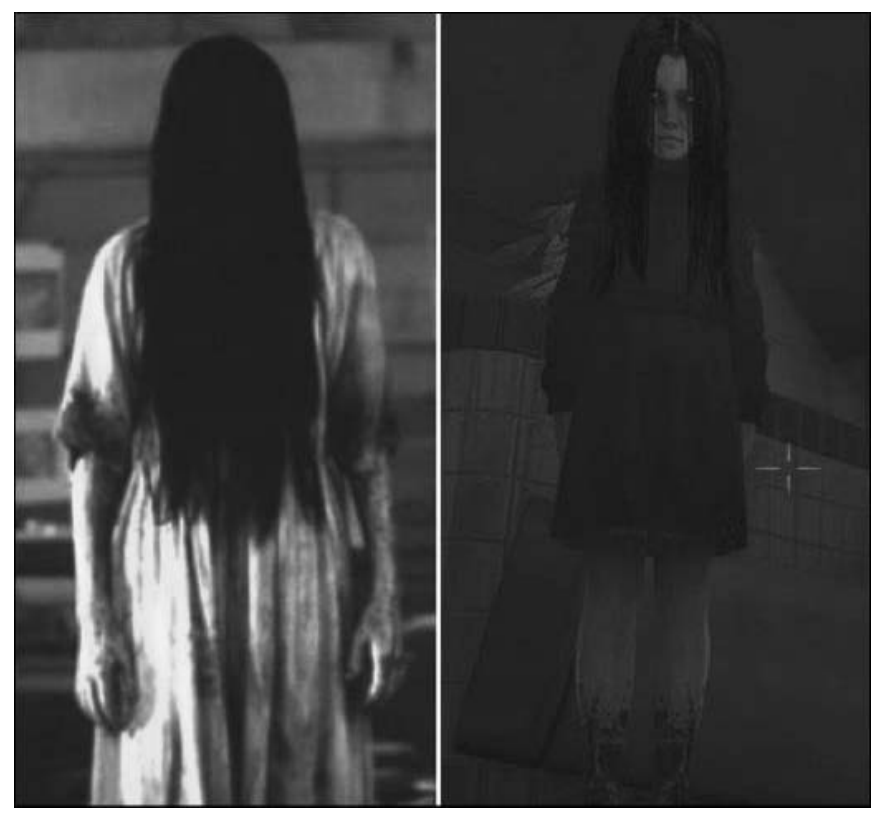

Рис. 2. Садако из «Звонка» и Альма из «F.E.A.R.»

Всё же в японской игровой индустрии имеется продукт, в котором можно отыскать крупицу японского фольклора. Речь идёт о не менее популярной серии хоррор-игр «Silent Hill». Так, в первой части при входе главного героя (Гарри Мейсона) в уборную школы Мидвид, он слышит плач маленькой девочки, что непосредственно является отсылкой на городскую легенду о туалетном призраке Ханако. Это обобщённый термин и в Японии им называют любые виды призраков, обитающих в женских уборных. Зачастую это жуткая девушка, погибшая насильственной смертью. Обычно у неё чёрные, закрывающие лицо длинные спутанные волосы и, как правило, какие-нибудь безобразия на теле. По легенде, если вы хотите увидеть Ханако, то нужно всего лишь постучать в уборной в третью кабинку от входа и позвать призрака. Тогда жуткое существо обязательно покажет любопытному свой жуткий облик. И если жертва не успеет унести ноги, то будет тут же убита, причём самым изощрённым образом. Помимо первой части «Silent Hill» присутствием Ханако навивает в третьей части серии. Практически в самом начале в пустом, погружённом во тьму здании, когда в одной из женских уборных главная героиня (Хизер) постучит в запертую кабинку, то внезапно послышится стук в ответ. Так же и во второй части при исследовании тёмных коридоров тюрьмы Толука можно наткнуться на дамскую уборную, в котором как раз третья кабинка от входа заперта. Может показаться, что внутри никого нет, так как, постучавшись в дверь, никто не отвечает. Однако спустя некоторое время игрок внезапно услышит громкий звук удара.

В Японии число 4 считается несчастливым числом, числом смерти, в связи с чем редко можно увидеть лифты с кнопкой 4. В самом начале первой части «Silent Hill» становится ясно, что у локации больницы «Alchemilla» всего три этажа. Однако, побывав на третьем этаже, и, вернувшись в лифт больницы, игрок обнаруживает кнопку с числом 4, которой раннее не было (см. Рис.3). Если рискнуть и подняться на четвёртый этаж, то игрок не сможет больше вернуться в лифт, ему остаётся только скитаться по тёмному коридору с тяжёлыми испытаниями (см. рис. 4).
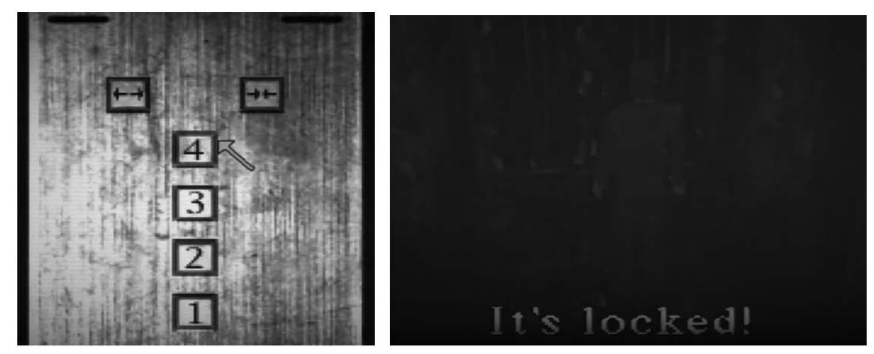

Рис. 3. Появление новой кнопки Рис. 4. «Заперто!»

Благодаря вышеперечисленным внедрений частиц японской культуры в игры, люди постепенно избавляются от стереотипного мышления касательно другого этноса. Наоборот, такой подход японских компаний в создании своих продуктов побуждает игроков ознакомиться с чем-то новым для себя, связанным с культурой и бытом страны всходящего солнца.

\section{Зак^ючение}

Подводя итог, можно сказать, что японское экономическое чудо дало мощный толчок формированию игровой индустрии страны восходящего солнца. Ибо и по сей день за её пределами японские видеоигры имеют большой спрос, вызванный индивидуальным подходом японцев к созданию продуктов, а также внедрёнными в игры элементами японской культуры. Это приводит к тому, что на Западе всё больше и больше людей приобщаются к культуре Японии, открывая для себя что-то новое. 


\section{ЛИТЕРАТУРА}

1. Веб-сайт [Электронный ресурс] - Режим для доступа: https://dtf.ru/gamedev/19918-osobennost-i-privlekatelnost-yaponskih-igr-mozhno-sravnit-sramenom (дата обращения - 23.04.2021)

2. Веб-сайт [Электронный ресурс] - Режим для доступа: https://dtf.ru/gameindustry/294571-igrovaya-industriya-za-2020-god-v-cifrah-infografika-otgamesindustry-biz (дата обращения - 23.04.2021)

3. Билоброва А.Е. Ключевые факторы развития игровой индустрии Японии // URL: https://cyberleninka.ru/article/n/klyuchevye-faktory-razvitiya-igrovoyindustrii-yароnii (дата обращения - 23.04.2021)

4. Валиахметова Г.Н. Особенности становления и развития индустрии видеоигр Японии в последней четверти XX-XXI веке / Г.Н. Валиахметова, А.Е. Билоброва // Научный диалог. — 2019. — № 11. — C. 245—257. — D01: 10.24224/2227-1295-2019-11-245-257. (дата обращения - 23.04.2021)

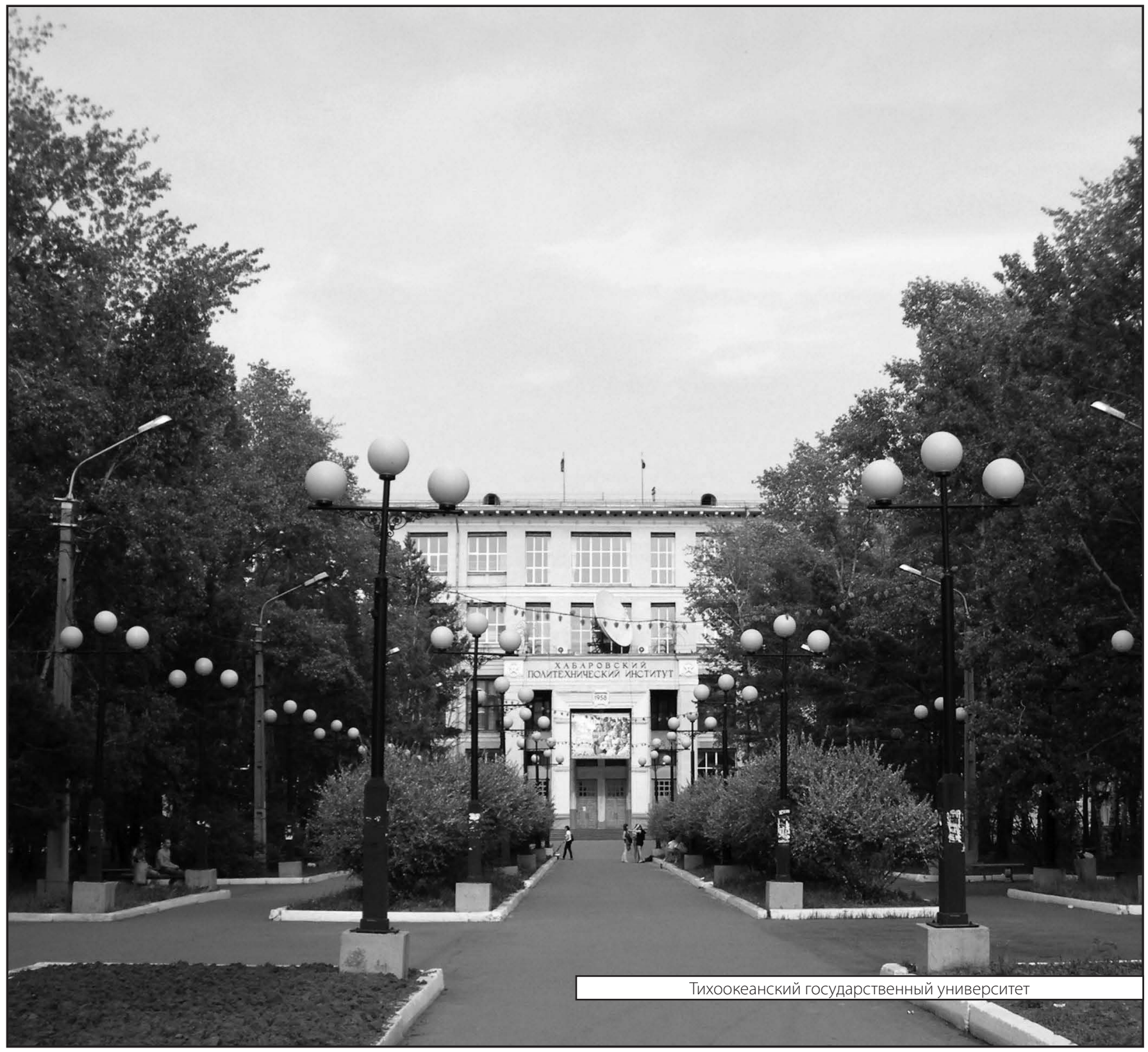

